\title{
Desiliconization Reaction of Pig Iron with High FeO Containing Blast Furnace Slag under Pressurized and Coke-coexisting Condition
}

\author{
Chisato YAMAGATA, Yoshimasa KAJIWARA, Shinichi SUYAMA and Takahisa MIYAKE1)
}

Project Promotion Department, Iron and Steel Research Laboratories, Research and Development Division, Sumitomo Metal Industries, Ltd., Sunayama, Hasaki-cho, Kashima-gun, Ibaraki-ken, 314-02 Japan. Sumitomo Metal Industries, Ltd., Minato, Wakayama, Wakayama-ken, 640 Japan.

1) Iron Making Department, Wakayama Steel Works,

(Received on December 5, 1989; accepted in the final form on March 9, 1990)

\begin{abstract}
For the quantitative investigation of the desiliconization inside blast furnace by the iron oxide injection through tuyeres, fundamental researches on the desiliconization reaction by high $\mathrm{FeO}$ containing slag under pressurized and cokecoexisting condition were performed by the use of a pressurized high frequency furnace. Under coke-coexisting condition, FeO not only reacts with silicon in hot metal but also simultaneously reacts with coke through the direct reduction reaction and the decrease of temperature and the increase of total pressure accelerates the desiliconization reaction through suppression of the direct reduction reaction. The increase of the amount of slag and the increase of slag basicity result in the enhancement of the desiliconization.

Based on the results of fundamental researches, an unsteady state desiliconization mathematical model was developed with consideration of the coupled reactions of desiliconization and direct reduction and successively applied to the quantitative analysis of the coupled reactions.

A test operation with dry iron ore dust was performed under almost constant pig iron temperature at Wakayama No. 4 blast furnace. A decrease of silicon content of $0.09 \%$ was obtained by the iron ore injection rate of $32 \mathrm{~kg} / \mathrm{pt} \mathrm{without} \mathrm{carry-}$ over of the injected iron ore to the hearth. Accordingly, the desiliconization by the iron ore injection was verified in the commercial test operation.
\end{abstract}

KEY WORDS: ironmaking; blast furnace process; desiliconization reaction; iron ore injection; direct reduction reaction; $\mathrm{FeO}$.

\section{Introduction}

From viewpoint of the total cost reduction in the ironmaking through steelmaking process, the reduction of silicon content in pig iron has been intended. The desiliconization outside blast furnace, so called pretreatment of pig iron as well as the desiliconization inside blast furnace has been developed. As one of the means for the latter process, the injection of iron oxide into blast furnace has been tested in some commercial blast furnaces with confirmation of the reduction of silicon content in pig iron. ${ }^{1-3)}$

However, fundamental researches on the desiliconization reaction of pig iron with high $\mathrm{FeO}$ containing slag have been scarecely performed. ${ }^{4-6)}$ Further, most researches ${ }^{4,6)}$ were performed under oxidizing condition outside blast furnace. Therefore, the decrease of the desiliconization efficiency of the injected iron ore caused by the direct reduction with coke is required to be clarified under pressurized and cokecoexisting condition as is the case for inner state condition of blast furnace.

In addition, although a test injection of iron ore into a commercial blast furnace was performed, the decrease of pig iron temperature caused by the heat of fusion of iron ore was not fully compensated. As a result, the reason for the decrease of silicon content by the iron ore injection was attributed to the decrease of pig iron temperature instead of the desiliconization reaction. ${ }^{1)}$

Therefore, in this study, fundamental researches on the desiliconization reaction of pig iron by high $\mathrm{FeO}$ containing slag under pressurized and coke-coexisting condition in blast furnace were performed with use of a pressurized high frequency furnace. The quantitative analyses were carried out by the use of an unsteady state mathematical model with consideration of the coupled reactions of the desiliconization and the direct reduction. Furthermore, an injection test of iron ore dust at Wakayama No. 4 blast furnace was performed under almost constant pig iron temperature.

\section{Experimental Procedure}

The experimental apparatus used in the fundamental experiments was a pressurized high frequency melting furnace of $30 \mathrm{kVA}$ at $3100 \mathrm{~Hz}$ as shown in Fig. 1. To avoid the contamination of the sample with the crucible material, the sample was contained in a magnesia crucible and a graphite crucible was placed outside the magnesia crucible to accelerate the melting of slag under intended temperature.

A $2 \mathrm{~kg}$ pre-melted metal sample of predetermined 


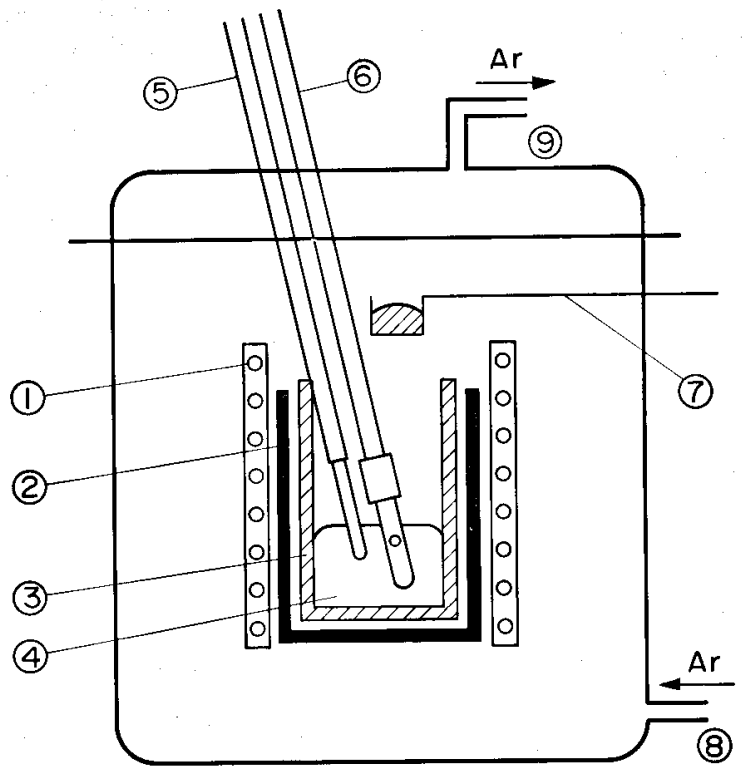

$\begin{array}{ll}\text { (1) High frequency coil } & \text { (6) Metal sampling device } \\ \text { (2) Graphite crucible } & \text { (7) Bucket for slag addition } \\ \text { (3) Magnesia crucible } & \text { (8) Gas inlet } \\ \text { (4) Hot metal } & \text { (9) Gas outlet } \\ \text { (5) Thermocouple } & \end{array}$

Fig. 1. Experimental apparatus.

composition was placed into the magnesia crucible and was heated up under argon atmosphere with flow rate of $20 \mathrm{~N} l / \mathrm{min}$. When the temperature of the sample reached the predetermined value, synthetic slag containing high $\mathrm{FeO}$ as the desiliconization agent was added to the metal sample by the use of a bucket prepared above the crucible.

During the experiment, the metal was sampled by the use of a metal sampling device made of quartz at about $1 \mathrm{~min}$ interval. The temperature was monitored by both an immersion type thermocouple and a two-color thermometer.

The experimental conditions are summarized in Table 1. The effects of temperature $(T)$, total pressure $\left(P_{T}\right)$, initial silicon content in hot metal, amount of slag, slag composition, amount of coke addition and coke size were investigated. Encircled values in Table 1 indicate the base experimental condition and were selected for the probable condition outside the raceway of blast furnace. The added coke was prepared from commercially used coke through grinding and sieving.

Table 2 shows the composition of hot metal prepared through pre-melting. Carbon, manganese, phosphorous and sulfur in hot metal are nearly in the same level of commercially produced pig iron. Only silicon content in hot metal was changed at 3 levels for investigation.

Slag used in the experiment is synthetic slag obtained from pre-melting of reagent mixture of $\mathrm{CaCO}_{3}$, $\mathrm{SiO}_{2}$ and $\mathrm{FeO}$.

\section{Experimental Results}

\subsection{Effects of Temperature and Total Pressure}

The effects of temperature and total pressure on
Table 1. Experimental conditions

\begin{tabular}{l|c}
\hline Items & Values \\
\hline Temperature $\left.\quad{ }^{\circ} \mathrm{C}\right)$ & $1400,1500,1600$ \\
Total pressure $\left(\mathrm{kgf} / \mathrm{cm}^{2} \mathrm{G}\right)$ & $0.5,3.0$ \\
Initial Si content $(\%)$ & $0.53,1.03,2.05$ \\
Amount of slag (g) & $100,200,300$ \\
Slag composition & $\mathrm{FeO}-\mathrm{CaO}-\mathrm{SiO}_{2}$ \\
Amount of coke oddition $(\mathrm{g})$ & $\mathrm{O}, 5,10$ \\
Coke size (mesh) & $-5 \sim+16, \sim,-200$ \\
\hline \multicolumn{2}{r}{ Base condition }
\end{tabular}

Table 2. Composition of hot metal used for the experiments. (\%)

\begin{tabular}{cccccc}
\hline & \multicolumn{5}{c}{ Element } \\
\cline { 2 - 6 } No. & $\underline{\mathrm{C}}$ & $\underline{\mathrm{Si}}$ & $\underline{\mathrm{Mn}}$ & $\underline{\mathbf{P}}$ & $\underline{\mathrm{S}}$ \\
\hline 1 & 3.90 & 2.05 & 0.54 & 0.123 & 0.037 \\
2 & 4.00 & 1.03 & 0.42 & 0.104 & 0.034 \\
3 & 3.89 & 0.53 & 0.54 & 0.118 & 0.031 \\
\hline
\end{tabular}

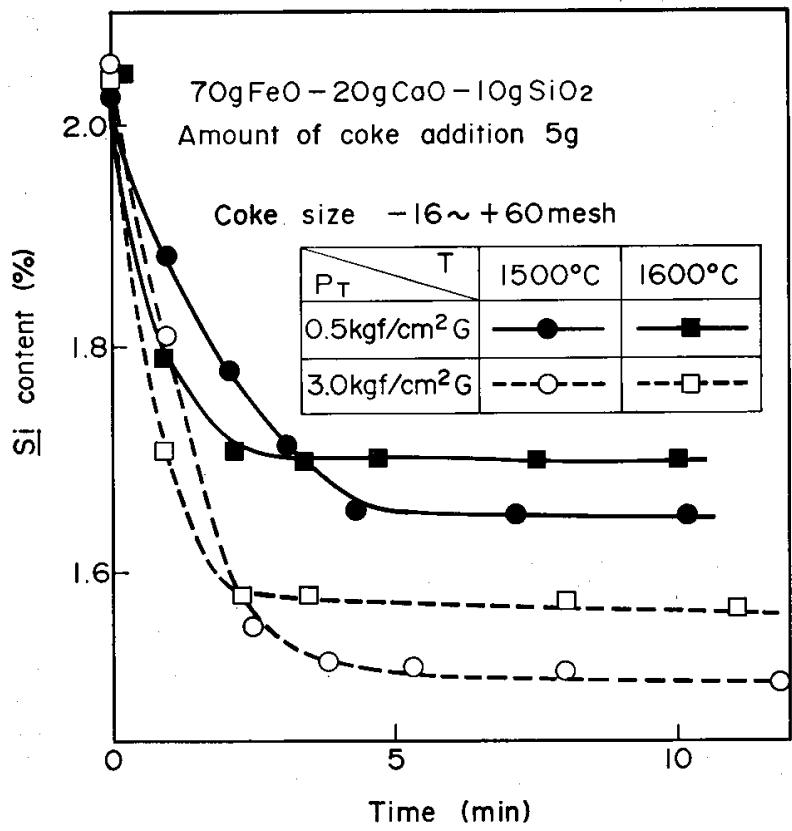

Fig. 2. Effects of temperature and total pressure on silicon content in hot metal.

silicon content are shown in Fig. 2. In order to simulate the existence of coke in blast furnace, coke addition (amount: $5 \mathrm{~g}$, size: $-10 \sim+60$ mesh) was carried out.

In case of high reaction temperature, the increase of mass transfer coefficients in both metal phase and slag phase accelerates the desiliconization reaction rate at the initial stage of the reaction. However, because of the rapid progress of the direct reduction reaction, the consumption of $\mathrm{FeO}$ or the desiliconization agent is rapid and the desiliconization reaction ceased to proceed. As a result, the final silicon content in hot metal is high. 
The increase of the total pressure suppresses the direct reduction reaction, as can be presumed from Eq. (4) to be described in Sec. 4.1, and decreases the final silicon content. On the other hand, under low pressure of $0.5 \mathrm{kgf} / \mathrm{cm}^{2} \mathrm{G}$, significant foaming of slag associated with $\mathrm{CO}$ gas generation by the direct reduction reaction was observed. The acceleration of the direct reduction reaction under low total pressure was also confirmed by the increase of waste gas volume as well as the increase of $\mathrm{CO}$ gas content in the waste gas.

\subsection{Effect of Initial Silicon Content}

The effect of initial silicon content on the amounts of the decarburization $(\Delta \underline{\mathrm{C}})$, the desiliconization $(\underline{\Delta \mathrm{Si}})$ and the demanganization $(\Delta \underline{\mathrm{Mn}})$ is shown in Fig. 3 under the condition that reaction temperature, total pressure and reaction time were selected as $1500^{\circ} \mathrm{C}$, $3 \mathrm{kgf} / \mathrm{cm}^{2} \mathrm{G}$ and $10 \mathrm{~min}$, respectively.

With the increase of the initial silicon content, $\Delta \underline{\mathrm{C}}$ is decreased and becomes negligible above silicon content of $1.0 \%$. Similar results were obtained for the case of coke addition (amount: $5 \mathrm{~g}$, size: $-16 \sim+60$ mesh).

In contrast, with the increase of initial silicon content, $\Delta \underline{\mathrm{Si}}$ is increased, while $\Delta \underline{\mathrm{Mn}}$ is reduced. The increase of initial silicon content increases the activity of silicon in metal and decreases the activity of manganese in metal. As a result, the desiliconization reaction is enhanced, while demanganization reaction is suppressed.

\subsection{Effect of Amount of Slag and Slag Composition}

Fig. 4 shows the effect of the amount of slag on $\Delta \underline{\mathrm{Si}}$. With the increase of the amount of slag, $\Delta \underline{\mathrm{Si}}$ was increased. This is because that the thermodynamic equilibrium controls the final distribution ratio of silicon in hot metal and slag.

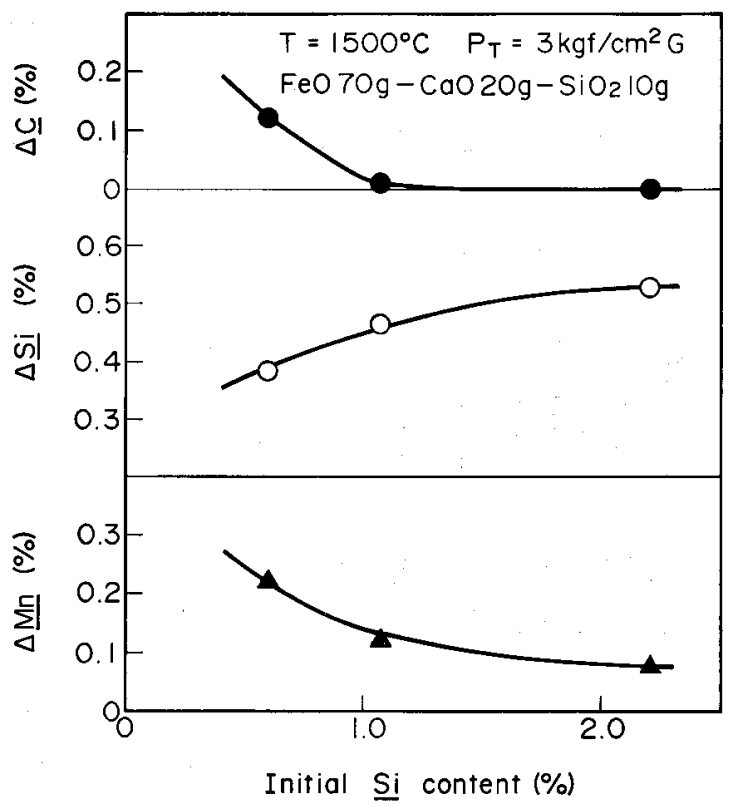

Fig. 3. Effect of initial silicon content on $\Delta \underline{\mathrm{C}}, \Delta \underline{\Delta} \underline{\mathrm{i}}$ and $\Delta \underline{\mathrm{Mn}}$.
In Fig. 5, the effect of slag basicity $\left(\mathrm{CaO} / \mathrm{SiO}_{2}\right)$ on $\Delta \underline{\mathrm{Si}}$ is shown under constant $\mathrm{FeO}$ content of $70 \mathrm{~g}$ in slag. The increase of slag basicity causes both the reduction of $\mathrm{SiO}_{2}$ activity in the initial slag and the increase of the mass transfer coefficient of $\mathrm{SiO}_{2}$ in the slag phase and results in the enhancement of the desiliconization reaction. Since the enhancement of the desiliconization reaction by the increase of basicity in slag is significant, the control of basicity in the desiliconization agent in the commercial operation should paid more attention.

The effect of FeO content in slag on silicon content in hot metal is shown in Fig. 6 under constant basicity

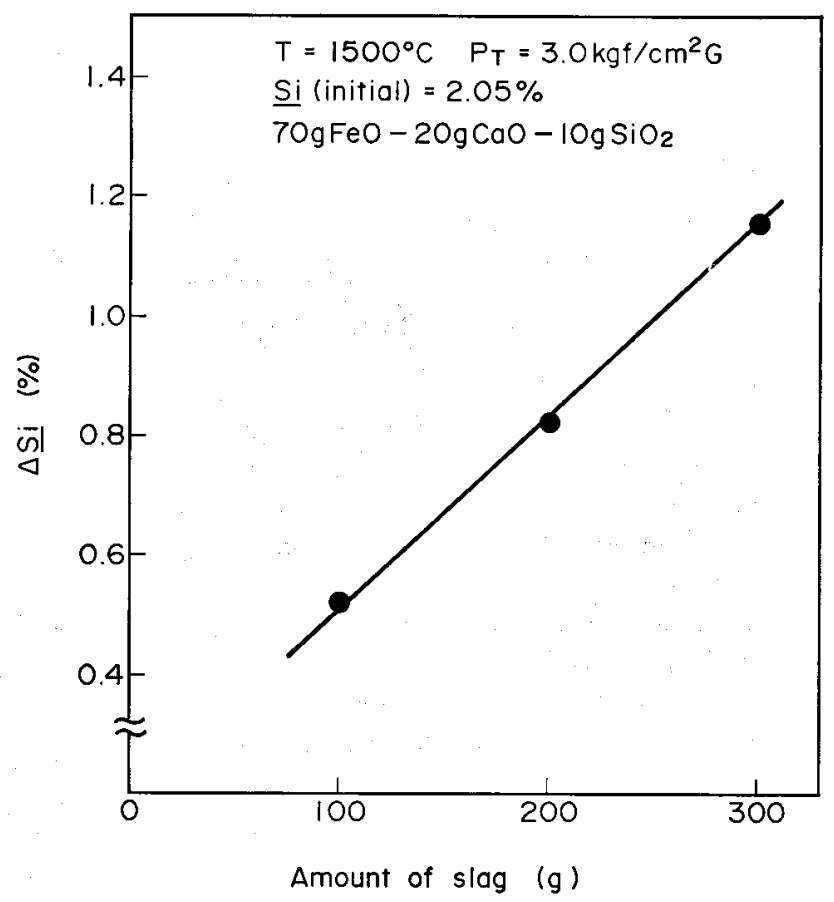

Fig. 4. Effect of amount of slag on $\Delta \underline{\text { Si}}$.

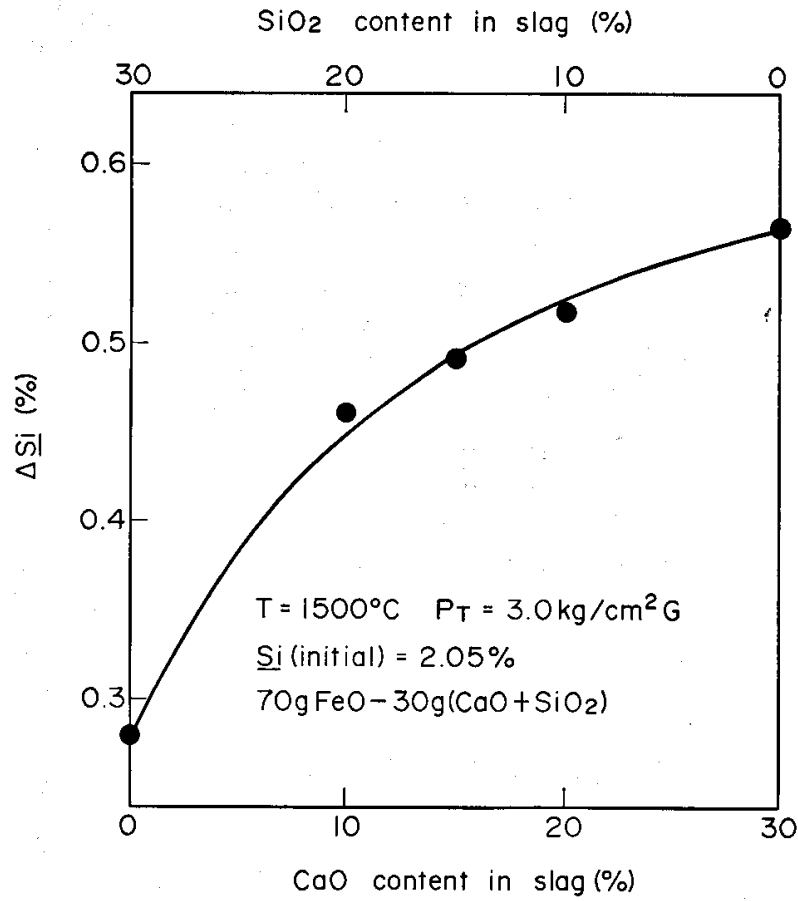

Fig. 5. Effect of slag basicity on $\Delta \underline{\mathbf{S}}$. 
of slag (1.0). By the increase of $\mathrm{FeO}$ content in slag, the desiliconization reaction rate at the initial stage is increased and the sufficient amount of $\mathrm{FeO}$ causes the reduction of the final silicon content.

\subsection{Effect of Coke Addition}

In order to simulate the existence of coke in the actual blast furnace, coke of various amount was added with the desiliconization agent and the experimental results are shown in Fig. 7 together with the change of coke size as a parameter. With the increase of the amount of coke addition, $\Delta \mathrm{Si}$ is decreased. In case of smaller coke size, the decrease of $\Delta \underline{\mathrm{Si}}$ is noticeable because of the enhancement of the

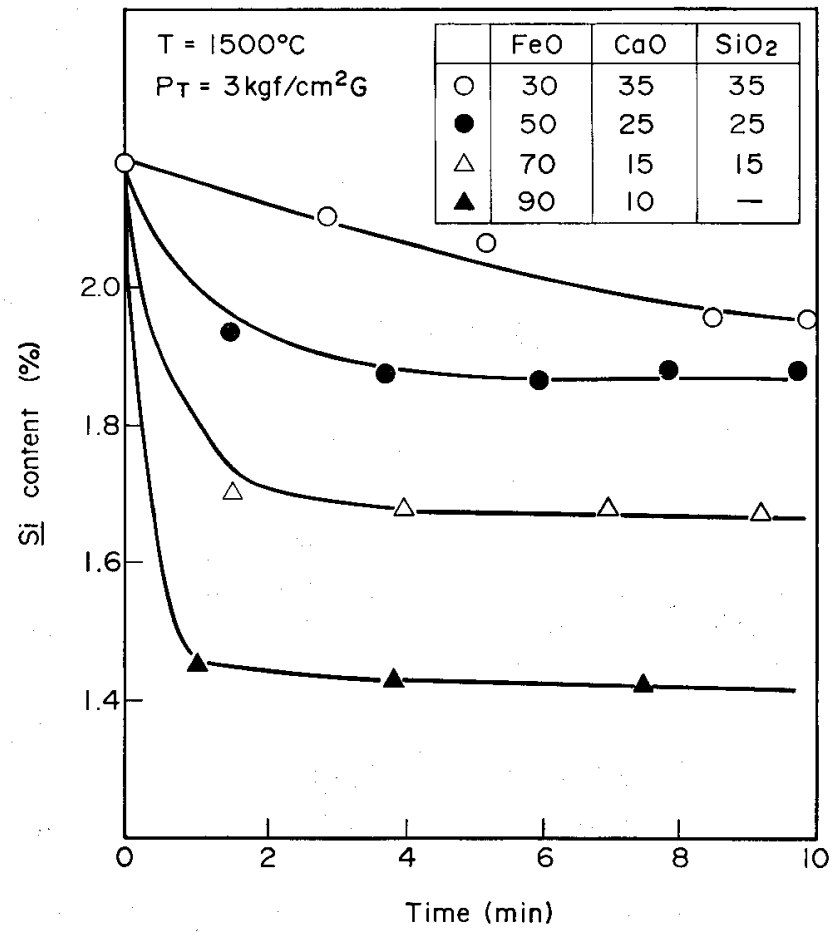

Fig. 6. Effect of $\mathrm{FeO}$ content in slag on silicon content in hot metal.

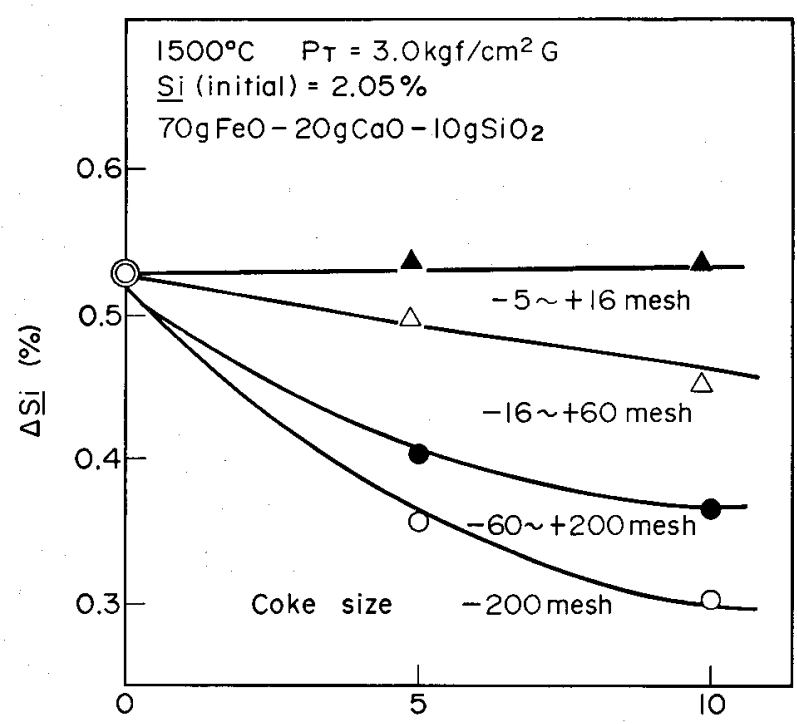

Amount of coke addition $(\mathrm{g})$

Fig. 7. Effects of coke addition and coke size on $\Delta \underline{\mathrm{Si}}$. direct reduction of $\mathrm{FeO}$ with larger coke-slag interfacial area. On the contrary, in case of $-5 \sim+16$ mesh coke size, $\Delta \underline{\mathrm{Si}}$ is maintained almost constant regardless of the amount of coke addition. Therefore, the direct reduction reaction of injected $\mathrm{FeO}$ outside the raceway in the actual operation seems to be greatly dependent on the amount of fine coke instead of lump coke.

\section{Desiliconization Mathematical Model}

With use of the former approach, 5) an unsteady state desiliconization mathematical model was developed for the system.

\subsection{Reactions Involved in the Desiliconization}

Based on the experimental results shown in Fig. 3 under the simulated blast furnace condition near raceway of silicon content level of $2.05 \%$, the desiliconization reaction expressed by Eq. (1) and the demanganization reaction expressed by Eq. (2) were considered to be involved in the slag-metal reaction, while the decarburization reaction in hot metal was disregarded over silicon content of $1 \%$ region. Further, in case of coke addition, the direct reduction of $\mathrm{FeO}$ in slag with coke was assumed to proceed with simultaneous 2 reactions, that is, the gas reduction reaction expressed by Eq. (3) and the solution loss reaction expressed by $\mathrm{Eq}$. (4).

4.1.1. Slag-Metal Reaction (at the Slag-Metal Interface)

1) Desiliconization reaction

$$
\underline{\mathrm{Si}}+2(\mathrm{FeO})=\left(\mathrm{SiO}_{2}\right)+2 \mathrm{Fe}
$$

2) Demanganization reaction

$$
\underline{\mathrm{Mn}}+(\mathrm{FeO})=(\mathrm{MnO})+\mathrm{Fe}
$$

4.1.2. Slag-Coke Reaction (at the Slag-Coke Interface)

1) Gas reduction reaction

$$
(\mathrm{FeO})+\mathrm{CO}(g)=\mathrm{Fe}+\mathrm{CO}_{2}(g)
$$

2) Solution loss reaction

$$
\mathrm{C}(s)+\mathrm{CO}_{2}(g)=2 \mathrm{CO}(g)
$$

\subsection{Outline of the Desiliconization Mathematical Model}

\subsubsection{Slag-Metal Reaction}

The schematic diagram of the desiliconization mathematical model is shown in Fig. 8. For the slagmetal reaction, the double layer theory was adopted and the mass transfer process both in the slag film and in the metal film and the interfacial reaction process were considered. Therefore, the elemental processes of the slag-metal reaction consist of the following 4 processes.

(1) Mass transfer of reactant silicon and manganese in hot metal to the reaction interface through the metal film

$$
\mathcal{N}_{j}^{m}=A \cdot k_{j}^{m} \cdot\left(C_{j}^{m}-C_{j \oplus i}^{m}\right)
$$

(2) Mass transfer of reactant $\mathrm{FeO}$ in slag bulk to the 


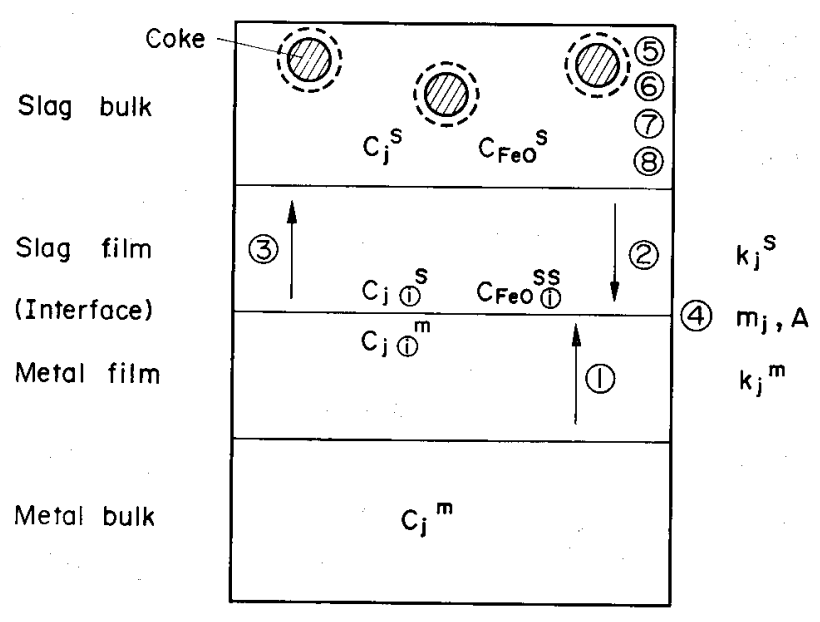

Fig. 8. Schematic diagram of desiliconization mathematical model.

reaction interface through the slag film

$$
\mathcal{N}_{\mathrm{FeO}}=A \cdot k_{\mathrm{FeO}} \cdot\left(C_{\mathrm{FeO}}-C_{\mathrm{FeO}(\mathrm{i})}\right)
$$

(3) Mass transfer of products $\mathrm{SiO}_{2}$ and $\mathrm{MnO}$ from the reaction interface through the slag film

$$
\mathcal{N}_{j}^{s}=A \cdot k_{j}^{s} \cdot\left(C_{j(1)}^{s}-C_{j}^{s}\right)
$$

(4) Interfacial reaction

$$
\begin{aligned}
& m_{1}=C_{\mathrm{SiO}_{2}(1)} /\left(C_{\mathrm{FeO}(1)}^{2} \cdot C_{\mathrm{Si}(1)}\right) \\
& m_{2}=C_{\mathrm{MnO}(\mathrm{i})} /\left(C_{\mathrm{FeO}(1)} \cdot C_{\mathrm{Mn}(\mathrm{i})}\right)
\end{aligned}
$$

The interfacial reaction was assumed to be in local equilibrium because of the high reaction rate at elevated temperatures around $1500^{\circ} \mathrm{C}$.

The direct reduction reaction of $\mathrm{FeO}$ in slag with coke is assumed to occur in the bulk of slag as will be mentioned next.

\subsubsection{Slag-Coke Reaction}

Fig. 9 schematically shows the direct reduction reaction of $\mathrm{FeO}$ in slag with coke in the bulk of slag. Coke in the slag bulk is assumed to be consumed concentrically from the surface. The mass transfer process both in the slag film and in the gas film, interfacial reaction process both at the gas-coke interface and at the gas-slag interface were considered as follows.

(5) Mass transfer of reactant FeO in slag to the reaction interface through the slag film

$$
\mathcal{N}_{\mathrm{FeO}}^{\prime}=A^{\prime} \cdot k_{\mathrm{FeO}} \cdot\left(C_{\mathrm{FeO}}-C_{\mathrm{FeO}(1)}^{\prime}\right)
$$

(6) Mass transfer of $\mathrm{CO}$ gas and $\mathrm{CO}_{2}$ gas through the gas film

$$
\begin{aligned}
& \mathcal{N}_{\mathrm{CO}}=A^{\prime} \cdot k_{\mathrm{CO}} \cdot\left(C_{\mathrm{CO} \oplus}-C_{\mathrm{CO}}\right) \\
& \mathcal{N}_{\mathrm{CO}_{2}}=A^{\prime} \cdot k_{\mathrm{CO}_{2}} \cdot\left(C_{\mathrm{CO}_{2}}-C_{\mathrm{CO}_{2} \uparrow}\right)
\end{aligned}
$$

(7) Interfacial reaction at the gas-coke interface

$$
m_{3}=C_{\mathrm{CO}(1)}^{2} / C_{\mathrm{CO}_{2}(1)}
$$

(8) Interfacial reaction at the gas-slag interface

$$
m_{4}=C_{\mathrm{CO}_{2}} /\left(C_{\mathrm{CO}} \cdot C_{\text {'eo(i) }}^{\prime}\right)
$$

The interfacial reactions both at the gas-coke and at the gas-slag interface were also assumed to be in

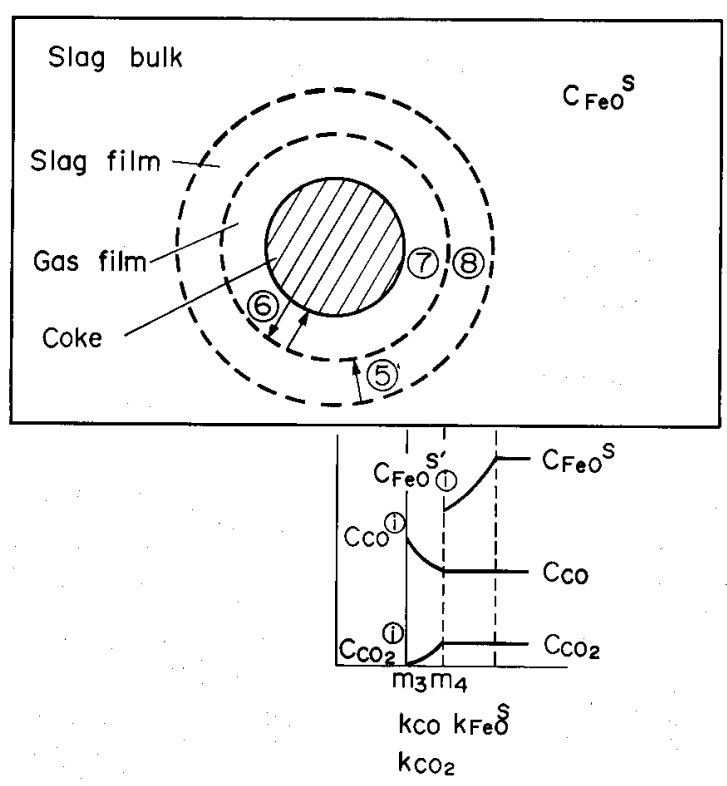

Fig. 9. Schematic diagram of coke-slag reaction modeling.

local equilibrium because of the high reaction rate at elevated temperatures.

Based on the equations obtained for the beforementioned (1) to (8) elemental processes, the transition of components of both metal and slag can be computed by the Runge-Kutta-Gill method with time step of $1 \mathrm{~s}$. In each time step, material balance of each element was strictly considered with progress of the reactions involved. Mass transfer coefficients and activity coefficients were evaluated by the same method performed before. ${ }^{5}$ )

\subsection{Calculated Example by the Mathematical Model}

An example of calculated results by the use of the mathematical model regarding the transition of the metal and slag components with progress of the reaction is shown in Fig. 10. Within $2 \mathrm{~min}$ after the initiation of the reaction, the desiliconization as well as the demanganization are significant. As a result, the decrease of $\mathrm{FeO}$ content in slag and the increase of $\mathrm{SiO}_{2}$ content and $\mathrm{MnO}$ content in slag are noticeable. Since the calculated results on the transition of metal components were in good agreement with experimental ones indicated by $\bigcirc$ in the figure, the validity of the mathematical model was confirmed.

\section{Test Results of Iron Ore Injection at Waka- yama No. 4 Blast Furnace}

For the investigation of the effect of the iron oxide injection on the desiliconization in actual blast furnace, a test operation was performed at Wakayama No. 4 blast furnace for 1 week both in October and in December, 1983.2) The iron oxide used for the test was dry iron ore dust collected from storage bins of the furnace and the composition is shown in Table 3. The test operation was performed under constant pig iron temperature with adjustment of blasting condition to eliminate the effect of the decrease of pig iron temperature caused by the iron ore injection on 


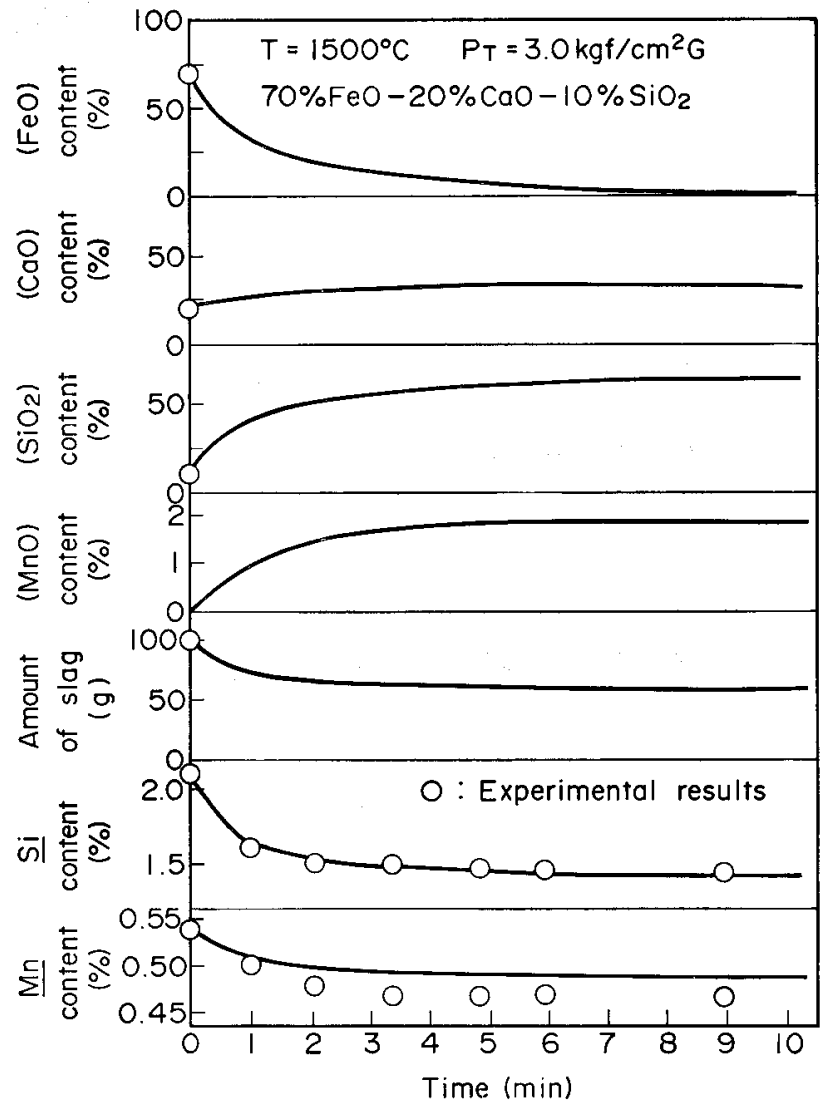

Fig. 10. Calculated example of the transition of slag and metal composition by the mathematical model.

Table 3. Composition of iron oxide used for the commercial test operation. (\%)

\begin{tabular}{cccccccccc}
\hline T.Fe & $\mathrm{FeO}$ & $\mathrm{SiO}_{2}$ & $\mathrm{Al}_{2} \mathrm{O}_{3}$ & $\mathrm{GaO}$ & $\mathrm{MgO}$ & $\mathrm{C}$ & $\mathrm{P}$ & $\mathrm{S}$ & $\mathrm{Zn}$ \\
\hline 50.3 & 4.7 & 6.2 & 1.9 & 7.0 & 0.8 & 6.8 & 0.06 & 0.08 & 0.13
\end{tabular}

the desiliconization.

Fig. 11 shows the relationship between the iron ore injection rate and silicon content in pig iron obtained in the test. The decrease of silicon content by $0.09 \%$ was obtained through the iron ore injection rate of 32 $\mathrm{kg} / \mathrm{pt}$. This value corresponds to the desiliconization efficiency of $29 \%$ calculated from material balance. This value may seem to be rather lower than the value obtained in Fig. 7, because the desiliconization efficiency is about $69 \%$ in case of $5 \mathrm{~g}$ coke addition and -200 mesh coke size. However, with consideration of the large segregation of fine coke around the raceway shell in actual blast furnace, the desiliconization efficiency obtained is reasonable. In any case, the amount and the size of fine coke near the raceway affect significantly the desiliconization efficiency in actual blast furnace.

$\mathrm{FeO}$ content in slag was almost unchanged with or without iron ore injection as shown in Fig. 12. Further, the desulfurization ratio was also unchanged irrespective of the iron ore injection as shown in Fig. 13.

Therefore, based on these test results, it is concluded that the injected iron ore is consumed both by the desiliconization reaction and by the direct reduc-

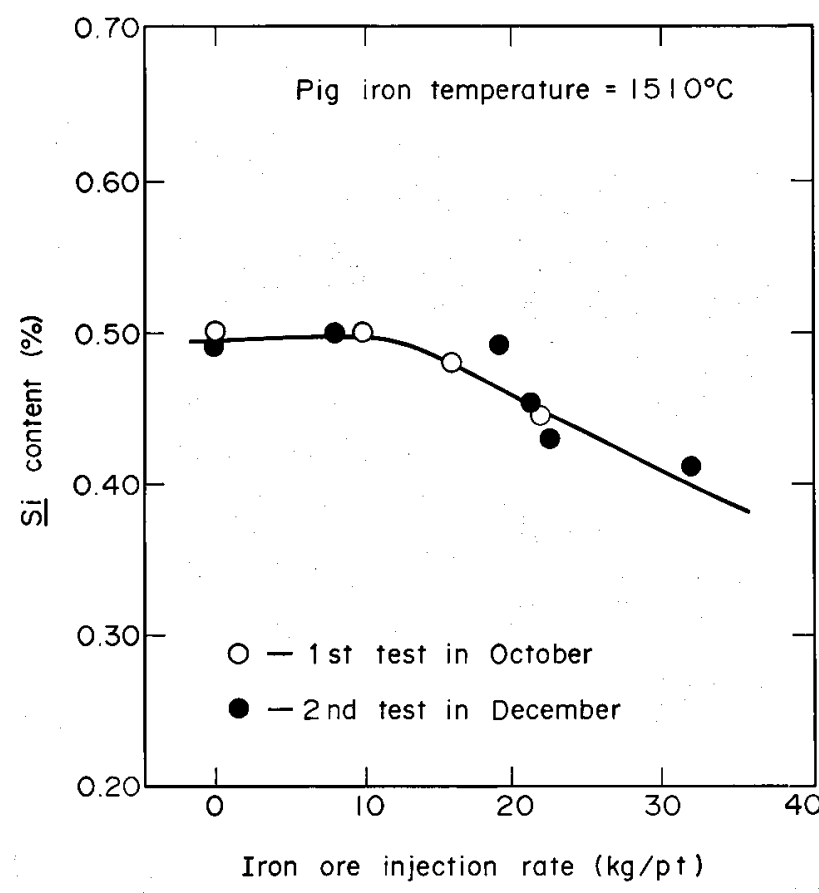

Fig. 11. Relationship between iron ore injection rate and silicon content in pig iron.

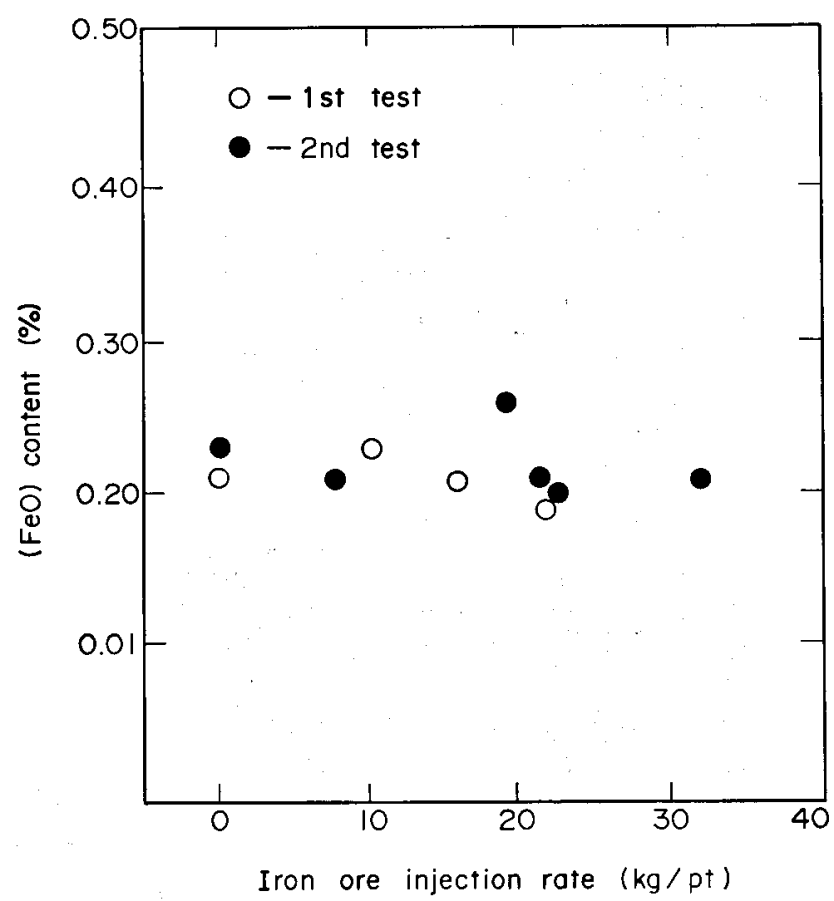

Fig. 12. Relationship between iron ore injection rate and $\mathrm{FeO}$ content in slag.

tion reaction with coke near the raceway and the carry-over of the injected iron ore into the hearth outside the raceway is negligible.

\section{Discussion on the Effect of Direct Reduction Reaction as Competitive Reaction}

For the quantitative investigation of the coupled reactions of the desiliconization and the direct reduction, the effect of coke addition on the direct reduction reaction and the desiliconization reaction was 


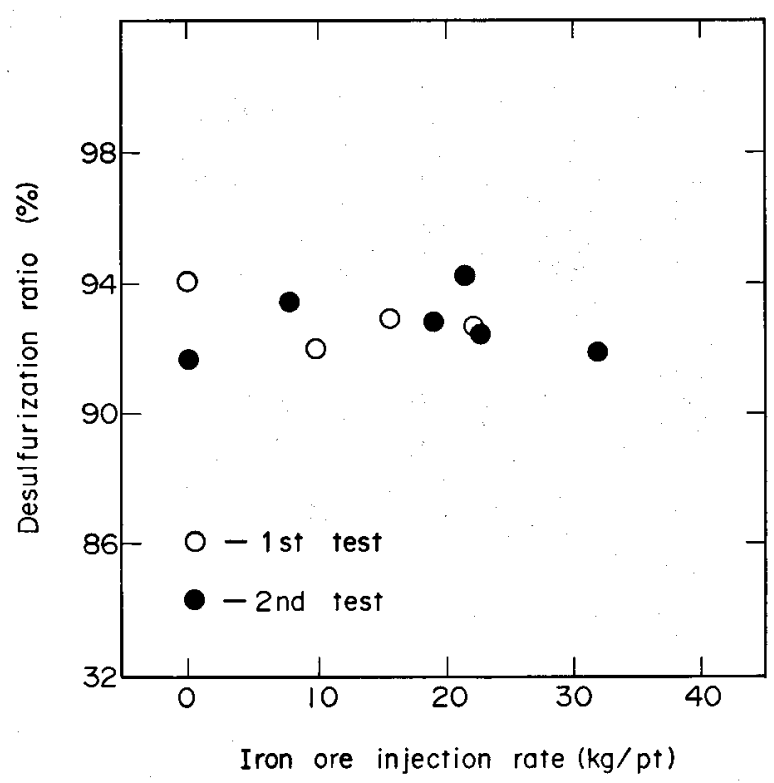

Fig. 13. Relationship between iron ore injection rate and desulfurization ratio.

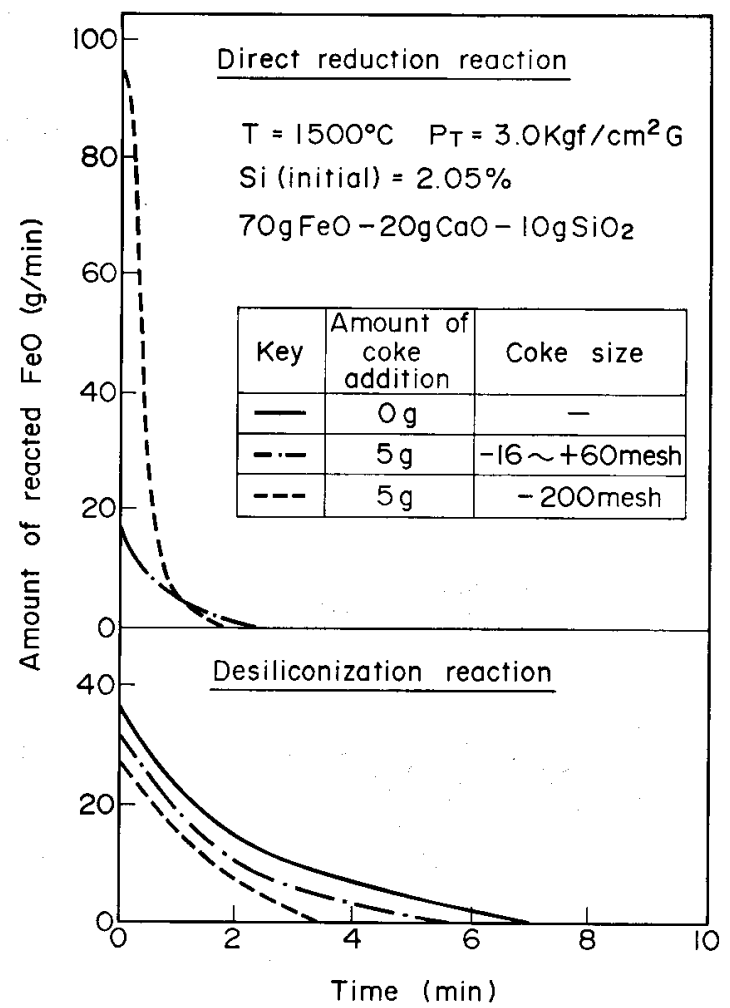

Fig. 14. Effect of coke addition on the direct reduction reaction and the desiliconization reaction.

evaluated by the mathematical model as shown in Fig. 14.

By $5 \mathrm{~g}$ coke addition with $-16 \sim+60$ mesh coke size, $\mathrm{FeO}$ reacts both with silicon in hot metal and with coke, although the consumption rate of $\mathrm{FeO}$ by the direct reduction reaction is about half of that by the desiliconization reaction. As a result, $\mathrm{FeO}$ is consumed more rapidly with coke addition than that without coke addition. With decrease of size of added coke, as also shown in Fig. 14, the direct reduction reaction significantly increases because of the significant increase of the interfacial area between coke and slag. On the other hand, the consumption rate of $\mathrm{FeO}$ by the desiliconization reaction decreases only slightly. As a result, the total reaction time became almost half in case of -200 mesh coke size.

Since $\mathrm{FeO}$ is more reducible than $\mathrm{MnO}$, the consumption rate of $\mathrm{FeO}$ with silicon in hot metal is larger than that of $\mathrm{FeO}$ and $\mathrm{MnO}$ mixture reported previously. ${ }^{5}$

\section{Conclusion}

In order to investigate the desiliconization inside blast furnace by the iron ore injection, fundamental researches were performed under pressurized and coke-coexisting condition with use of a pressurized high frequency furnace and a test operation with the injection of iron ore dust was performed at Wakayama No. 4 blast furnace. Through the fundamental researches and the commercial test operation, the following results were obtained.

(1) The existence of coke and the decrease of coke size enhance the direct reduction reaction and the desiliconization is suppressed.

(2) The decrease of temperature and the increase of total pressure enhance the desiliconization through suppression of the direct reduction reaction.

(3) The increase of initial silicon content accelerates the desiliconization reaction and decclerates the demanganization.

(4) The increase of the amount of slag and slag basicity enhances the desiliconization.

(5) An unsteady state desiliconization mathematical model was developed with consideration of the coupled reactions of the desiliconization and the direct reduction reaction based on the results of fundamental researches.

(6) The decrease of silicon content of $0.09 \%$ by the iron ore injection rate of $32 \mathrm{~kg} / \mathrm{pt}$ was obtained under almost constant pig iron temperature in the commercial test operation. Accordingly, the desiliconization by the injection of iron ore was verified in the commercial test operation.

\section{Nomenclature}

$A$ : interfacial area of slag-metal reaction $\left(\mathrm{cm}^{2}\right)$

$A^{\prime}$ : interfacial area of slag-coke reaction $\left(\mathrm{cm}^{2}\right)$

$C_{j}^{m}$ : molar concentration of $j$ component in metal bulk $\left(\mathrm{mol} / \mathrm{cm}^{3}\right)$

$C_{j}^{m}$ : $:$ molar concentration of $j$ component in metal at the slag-metal interface $\left(\mathrm{mol} / \mathrm{cm}^{3}\right)$

$C_{j}^{s}$ : molar concentration of $j$ component in slag bulk $\left(\mathrm{mol} / \mathrm{cm}^{3}\right)$

$C_{j \mathbb{Q}}^{*}$ : molar concentration of $j$ component in slag at the slag-metal interface $\left(\mathrm{mol} / \mathrm{cm}^{3}\right)$

$C_{\mathrm{Co}}$ : molar concentration of $\mathrm{CO}$ gas in gas bulk $\left(\mathrm{mol} / \mathrm{cm}^{3}\right)$

$C_{\mathrm{CO} 1}$ : molar concentration of $\mathrm{CO}$ gas at the gascoke interface $\left(\mathrm{mol} / \mathrm{cm}^{3}\right)$

$C_{\mathrm{CO}_{2}}$ : molar concentration of $\mathrm{CO}_{2}$ gas in gas bulk $\left(\mathrm{mol} / \mathrm{cm}^{3}\right)$

$C_{\mathrm{CO}_{2} \oplus}$ : molar concentration of $\mathrm{CO}_{2}$ gas at the gascoke interface $\left(\mathrm{mol} / \mathrm{cm}^{3}\right)$ 
$C_{\mathrm{F} \ominus \mathrm{O}}$ : molar concentration of $\mathrm{FeO}$ in slag bulk $\left(\mathrm{mol} / \mathrm{cm}^{3}\right)$

$C_{\mathrm{FeO}}$ : molar concentration of $\mathrm{FeO}$ in slag at the slag-metal interface $\left(\mathrm{mol} / \mathrm{cm}^{3}\right)$

$C_{\mathrm{FeO}(1)}^{\prime}$ : molar concentration of $\mathrm{FeO}$ in slag at the slag-coke interface $\left(\mathrm{mol} / \mathrm{cm}^{3}\right)$

$C_{\mathrm{Mno}(1)}$ : molar concentration of $\mathrm{MnO}$ in slag at the slag-metal interface $\left(\mathrm{mol} / \mathrm{cm}^{3}\right)$

$k_{\mathrm{CO}}$ : mass transfer coefficient of $\mathrm{CO}$ gas in gas film $(\mathrm{cm} / \mathrm{s})$

$k_{\mathrm{CO}_{2}}$ : mass transfer coefficient of $\mathrm{CO}_{2}$ gas in gas film $(\mathrm{cm} / \mathrm{s})$

$k_{\mathrm{FeO}}$ : mass transfer coefficient of $\mathrm{FeO}$ in slag film $(\mathrm{cm} / \mathrm{s})$

$k_{j}^{m}$ : mass transfer coefficient of $j$ component in metal film $(\mathrm{cm} / \mathrm{s})$

$k_{j}^{s}$ : mass transfer coefficient of $j$ component in slag film $(\mathrm{cm} / \mathrm{s})$

$m_{1}$ : equilibrium constant of reaction Eq. (1) expressed in molar content $(-)$

$m_{2}$ : equilibrium constant of reaction Eq. (2) expressed in molar content $(-)$

$m_{3}$ : equilibrium constant of reaction Eq. (3) expressed in molar content $(-)$

$m_{4}$ : equilibrium constant of reaction Eq. (4) expressed in molar content $(-)$

$\mathcal{N}_{j}^{m}$ : mass transfer rate of component $j$ in metal film (mol/s)

$\mathcal{N}_{j}^{s}$ : mass transfer rate of component $j$ in slag film at the slag-metal interface $(\mathrm{mol} / \mathrm{s}$ )
$\mathcal{N}_{\mathrm{FeO}}$ : mass transfer rate of $\mathrm{FeO}$ in slag film at the slag-metal interface $(\mathrm{mol} / \mathrm{s})$

$\mathcal{N}_{\mathrm{FeO}}^{\prime}$ : mass transfer rate of $\mathrm{FeO}$ in slag film at the slag-coke interface $(\mathrm{mol} / \mathrm{s})$

$\mathcal{N}_{\mathrm{Co}}$ : mass transfer rate of $\mathrm{CO}$ gas in gas film $(\mathrm{mol} / \mathrm{s})$

$\mathcal{N}_{\mathrm{CO}_{2}}$ : mass transfer rate of $\mathrm{CO}_{2}$ gas in gas film $(\mathrm{mol} / \mathrm{s})$

Suffixes

$j$ : designates components in either metal or slag in metal ( 1 for $\mathrm{Si}, 2$ for $\mathrm{Mn}$ )

in slag ( 1 for $\mathrm{SiO}_{2}, 2$ for $\mathrm{MnO}$ )

$m$ : designates the values for metal

$s:$ designates the values for slag

(1): designates the values at the interface

\section{REFERENCES}

1) M. Saino, K. Okumura, Y. Ikeda, T. Minakawa, K. Takeda and Y. Sakaguchi: "Fifth Int. Iron Steel Cong.", AIME Ironmaking Proc., 45 (1986), 519.

2) S. Mizuno, N. Hosoi, M. Motoshige, T. Miyake, H. Hakamura and C. Yamagata: Tetsu-to-Hagané, 70 (1984), S35.

3) K. Kushima, M. Naito, K. Shibata, H. Sato, H. Yoshida and M. Ichida: AIME Ironmaking Proc., 47 (1988), 457.

4) K. Narita, T. Makino, H. Matsumoto, A. Hikosaka and J. Katsuda: Tetsu-lo-Hagané, 69 (1983), 1722.

5) C. Yamagata, Y. Kajiwara and S. Suyama: Trans, Iron Steel Inst. Jpn., 28 (1988), 83.

6) W. Pan, M. Sano, M. Hirasawa and K. Mori: Tetsu-toHagané, 74 (1988), 61. 